\section{RADIATION CHEMISTRY AT THE UNIVERSITY OF NOTRE DAME, INDIANA}

ATHOUG I, as Allsopp ${ }^{1}$ has recently indicated, A radiation chemistry is in reality an old subject, it has received its major impetus during the Second World War. Problems of the production of atomic energy and atomic power require information on the effects of high-energy radiation on structural materdals, coolants, moderators and chemicals and containers used in separation processes, as well as on the chemistry of nuclear recoils produced in the processes of radioactive decay or in processes for the separation of radioactive nuclides. Technological aspects of these problems have been handled primarily in the National Laboratories in the United States (Argonne, Oak Ridge and Brookhaven) and at the Chalk River Atomic Energy Establishment, Canada, and also at Harwell, England.

Significantly, academic institutions have confined their attention to non-secret, 'unclassified' fundamental investigations. Such a group is working with Dr. F. S. Dainton at Cambridge. Groups working in the United States include those at the Massachusetts Institute of Technology and Syracuse University. A group at the University of Notre Dame is a direct outgrowth of the activities of the Plutonium Project. That group has attempted to stimulate research in radiation chemistry in a variety of ways : by symposia, by research and by training of new personnel.

The seriousness with which radiation chemistry is considered in the United States is again emphasized by the announcement that the Radiation Chemistry Project at the University of Notre Dame will henceforth be operated under contract from the Atomic Energy Commission. With the stimulation and support of the Commission, Notre Dame will be the first academic institution to install a Van de Graaff generator exclusively for studies in radiation chem. istry and allied fields (for example, radiobiology). This generator will be housed in a new building to be added to the present chemistry building. Included in the new structure will be a radio-cobalt source room. Construction was to begin by October 1,1949 , and it is expected that the entire new installation will be in operation by May 1,1950 .

The stafi of the Radiation Chemistry Project includes Prof. Milton Burton (director) and Andrew J. Boyle (administrative director), Associate Prof. William H. Hamill and John L. Magee, and Assistant Prof. Russell R. Williams, jun. Also on the stafi are approximately fifteen graduate fellows and technicians. The number of the latter is not fixed, and it is expected that the increased funds available will lead to substantial increases in the staff.

Among the fields at present under investigation are the effects of high-energy radiation on ionic crystals and on organic compounds and solutions, 'hot-atom' chemistry, radiation chemical monitoring, theory of elementary physical processes, chemical behaviour of excited molecules and ions, stability of metastable ions, etc. Only non-secret work will be done under the auspices of the Atomic Energy Commission.

Prof. Burton will continue to direct systematic investigations in the radiation chemistry of organic compounds, ionic solids, and aqueous solutions, and will collaborate with Prof. Magee, who will direct research on theoretical problems. Prof. Hamill will direct work which emphasizes employment of radioisotopes in radiation chemistry, while Prof. Williams will direct studies primarily in 'hot-atom' chemistry and the behaviour of energetic radicals as well as continue work in pedagogic aspects of nuclear chemistry.

An interesting aspect of the work of the Radiation Chemistry Project at Notre Dame is the emphasis which is placed on employment of the mass spectro. meter, radioisotopes, and special arrangements of the glow-discharge in the elucidation of elementary processes.

'Brit. J. Radiology, 22, 183 (1949).

\section{ELECTRON DEFECT CENTRES IN ALKALI HALIDES}

\section{By J. ALEXANDER and Dr. E. E. SCHNEIDER King's College (University of Durham), Newcastle upon Tyne}

$\mathrm{T}$ HE absorption crirves of crystals of sodium and potassium Chloride coloured by X-rays obtained by Molnar ${ }^{1}$ have shown a rise in absorption towards the ultra-violyt edge (2,300 A.) of his spectral range. We have made measurements of this $V$-band ${ }^{2}$ extending dowy to 2,000 A. which have established that it is an essential feature of all photochemically coloured atkali halide crystals wholly complementary to the $F$-band in the visible spectrum. The $V$-band in the chlorides follows very closely the theoretical absorption curve of a single classical oscillator (Fig. 1). In potassium bromide it has two components, the relative intensity of which depends on the intensity of coloration (Fig. 2).

The position of the maximum and the half-width of the absorption (shown in the table) are character. istic of the crystals investigated. The results are independent of the state of purity of the crystals (indicated by the value of $k_{0}$ ) and of the irradiation conditions (for example, crystals of $10 \mathrm{~mm}$. $\times 5 \mathrm{~mm}$. $\times 1 \mathrm{~mm}$., 30-120 min. exposure to filtered X-rays from a crystallographic set, $50 \mathrm{kV}$, 20 m.amp., $\lambda<0.7$ A.).

TABLE SHOTING ABSORPTION FOR DIFFERENT ALKALI-HALIDE CRYSTALS COLOURED BY X-RAYS, $k_{0}$ IS THE ABSORPTION CONSTANT BEFORE X-IRRADIATION

\begin{tabular}{|c|c|c|c|c|}
\hline & \multicolumn{2}{|c|}{$\begin{array}{c}\text { Maximum of the } \\
\text { absorption band }\end{array}$} & $\begin{array}{c}\text { Half-width } \\
\text { of band in } \\
\mathrm{eV} .\end{array}$ \\
\hline Source & $k_{0}$ in $\mathrm{cm}^{-1}$ & in A. & in $\mathrm{eV}$. & \\
\hline $\begin{array}{c}\text { KCl } \\
\text { (synthetic) }\end{array}$ & 0.51 & 2.05 & 5.60 & 1.39 \\
$\begin{array}{c}\text { NaCl } \\
\text { (synthetic) }\end{array}$ & 1.30 & 2170 & 5.70 & 1.03 \\
$\begin{array}{c}\text { NaCl } \\
\text { (natural) }\end{array}$ & & & & \\
No. 1 & 3.61 & 2,170 & 5.70 & 1.03 \\
No.2 & 3.27 & 2,180 & 5.67 & 1.03 \\
KBr & 2.08 & 2,320 & 5.32 & 0.83 \\
(synthetic) & 2.08 & 2.580 & 4.77 & 0.86 \\
\hline
\end{tabular}

Experiments on the properties of X-ray coloured crystals, chiefly potassium chloride, associated with the $V$-band have yielded the following results.

Ageing Process. The $V$-absorption continues to grow after the end of X-ray exposure and, at room temperature, reaches a final steady value only after an ageing period of about twenty hours. The increase 
in absorption during this time is the greater the lower the temperature of the crystal during X-irradiation, ranging from 15 per cent for $-50^{\circ} \mathrm{C}$. to 8 per cent for $+20^{\circ} \mathrm{C}$. irradiation temperature.

Relation of $V$ - and $F$-centres. The number of $V$-absorption centres in 'aged' X-ray coloured crystals not previously exposed to visible or ultra-violet light is equal to the number of $F$-centres $\left(\sim 10^{12} \mathrm{~cm} .^{-3}\right.$ for $30 \mathrm{~min}$. X-ray exposure). This result is derived from the observed agreement between the products of maximum absorption and half-width of the two absorption bands on the assumption of equal oscillator strengths, an assumption which is reasonable in view of the 'classical' shape of both absorption curves, and of the experimental value $f=0.8$ for $F$-centres in potassium chloride ${ }^{3,4}$.

Bleaching by $F$-irradiation. The quantum efficiency of the bleaching of the $F$-absorption by irradiation in the $F$-band of freshly coloured crystals has an initial value of approximately 1 ; it decreases rapidly and reaches eventually a value as low as 0.005 . In aged crystals the initial rate of bleaching is considerably smaller. The $F$-bleaching is accompanied by the formation of secondary colour centres ( $M$ centres ${ }^{1,2}$ ) and also by a bleaching of the $V$-band. The rate of $V$-bleaching is at first much smaller than that of the $F$-band, but approaches it towards the final very slow phase of the bleaching process.

$V$-band Bleaching by V-irradiation and Restoration. Irradiation with ultra-violet light corresponding to the maximum of the $V$-band bleaches the $V$-absorption with a quantum efficiency approximately 1 without affecting the $F$-absorption. On cessation of the ultra-violet irradiation, the $V$-absorption returns gradually to its original value. At room temperature this restoration process occupies a period of two to three days.

Fast Bleaching by Combined V-ard $F$-irradiation. Simultaneous or successive irradiation in the $V$. and $F$-bands produces a very fast and complete bleaching of the crystal throughout the whole spectrum. An aged crystal first irradiated in the $V$-band bleaches during subsequent irradiation in the $F$-band at a quantum efficiency of approximately 1 ; that is, every electron liberated by the $F$-absorption is removed. This rapid bleaching goes on until the number of $F$-centres destroyed is equal to the number of $V$-quanta absorbed previously; after that, the bleaching continues at the very slow rate observed under normal conditions.

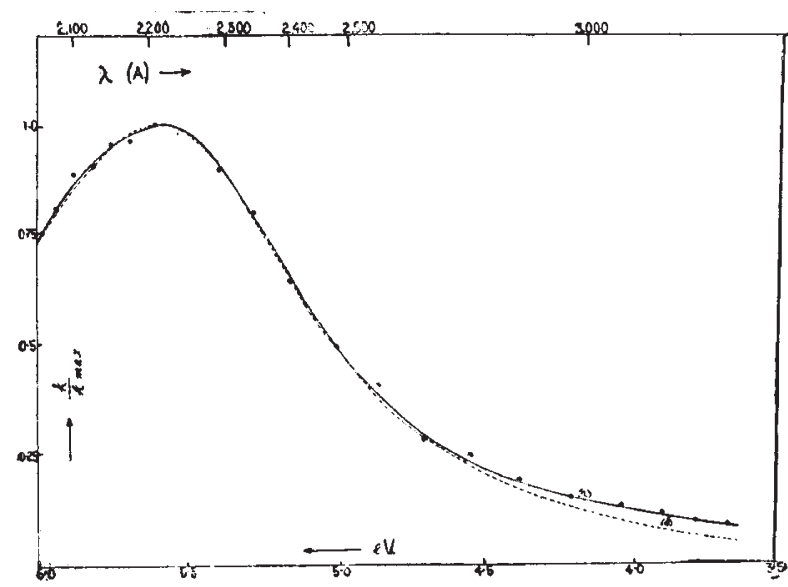

Fig. 1. V-absorption in $\mathrm{KCl}$. Temperature $21 \cdot 5^{\circ} \mathrm{C}$. $k$ max. (absorption constant at the maximum) $=5.76 \mathrm{~cm}^{-1}, 0-0-$, Experi mental curve; - - - - , theoretical curve

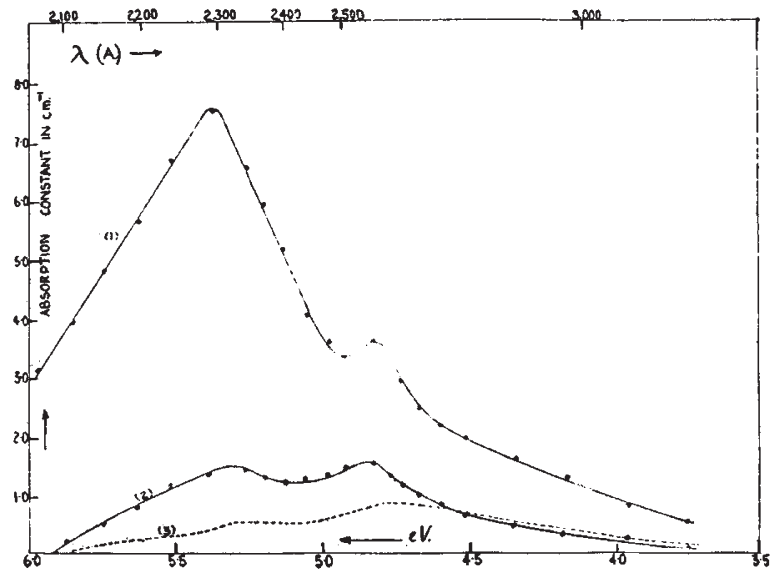

Fig. 2. V-absorption in $\mathrm{KBr}$. Temperature $21.5^{\circ} \mathrm{C}$. (1) High
concentration of centres;
(2) low concentration of centres ; concentration of centres; (2) low concentration of centres;
(3) (dotted) absorption curve cf stoichimetric excess of halogen in $\mathrm{KBr}$ crystal (Mollwo)

Isolation of $V$-centres. $F$-centres can be withdrawn from a coloured crystal if a strong electric field (about $2,000 \mathrm{volt} / \mathrm{cm}$.) is applied during irradiation in the $F$-band. Crystals treated in this way are left with only the $V$-band, which cannot be bleached permanently by light of any wave-length.

It is usually assumed that the essential photochemical action of $\mathrm{X}$-rays (or other ionizing radiation) on alkali halide crystals consists in the dissociation of halogen ions into electrons, forming $F$-centres and halogen atoms. Our experiments find a natural explanation if the $V$-band is associated with the presence of halogen atoms in the crystals, forming positive holes in the normal lattice. This interpretation, which mainly rests on the equality of the $V$ - and $F$-centre concentrations, is strongly supported by the agreement between the ultra-violet absorption observed by us in X-ray coloured crystals of potassium bromide and that observed by Mollwo ${ }^{5}$ in potassium bromide crystals containing excess bromine (see Fig. 2).

The bleaching experiments can be understood if it is assumed that in the normal $V$-centre state positive holes are bound in traps in the lattice where they are electrically neutralized, and thus have a very small capture cross-section accounting for the normal very slow bleaching of the $F$-band. The fast bleaching of the $F$-band in freshly coloured and $V$-irradiated crystals would have to be explained by the presence of free or untrapped positive holes which readily attract electrons and recombine with them to form halogen ions, and the ageing and restoration processes by a gradual filling or re-filling of the traps. Irradiation in the $V$-band is in this picture assumed to result in the formation of free positive holes. The two peaks of the $V$-band in potassium bromide and in potassium iodide containing excess iodine ${ }^{5}$, the energy separation of which agrees with that of the $2 P_{1 / 2}-2 P_{3 / 2}$ levels of free halogen atoms, should, therefore, be associated with a splitting of the end state of the absorption process rather than with a fine structure of the initial state, which corresponds to trapped positive holes, and is less likely to resemble the ground state of free halogen atoms.

1 Molnar, J. P., Ph.D. Thesis, Mass. Inst. Tech., 1940.

2 Seitz, F., Rev. Mod. Phys., 18, 384 (1946).

${ }^{3}$ Kleinschrod, F, G., Ann. Phys., 27,97 (1936).

'Mott, N. F,; and Gurney, R. W., "Electronic Processes in Iunic: Crystals;', 115.

${ }^{5}$ Mollwo, E., Ann. Phys., 29, 394 (1937). 